\title{
Evaluating sugarcane genotypes for genetic variation with differential sucrose accumulation using TRAP markers and partial Sai nucleotide polymorphism
}

\author{
Trin Srivong ${ }^{\mathrm{a}}$, Yun J. Zhu ${ }^{\mathrm{b}}$, Suchirat Sakuanrungsirikul ${ }^{\mathrm{c}}$, Chifumi Nagai ${ }^{\mathrm{b}}$, Manit Kosittrakun ${ }^{\mathrm{a}, *}$ \\ a Applied Taxonomic Research Center, Department of Biology, Faculty of Science, Khon Kaen University, \\ Khon Kaen 40002 Thailand \\ ${ }^{b}$ Hawaii Agriculture Research Center (HARC), Waipahu, HI 96797 USA \\ c Khon Kaen Field Crops Research Center, Department of Agriculture, Ministry of Agriculture and \\ Cooperatives, Khon Kaen 40000 Thailand
}

*Corresponding author, e-mail: manit.kosittrakun@fulbrightmail.org

Received 31 Jul 2018

Accepted 6 Jul 2019

\begin{abstract}
This study was conducted to characterize 17 sugarcane genotypes from Hawaii and Thailand using 12 target region amplification polymorphism (TRAP) markers and partial Sai nucleotide polymorphism. A total of 275 fragments were produced, of which $273(99.27 \%)$ were polymorphic. The polymorphic information content (PIC) ranged from $0.912-0.959$ with an average value of 0.938 . Genetic similarity (GS) by Dice's similarity coefficient ranged from $0.19-0.81$ with a mean of 0.44 . The 14 sugarcane genotypes from the Thailand collection with different sugar content were also assessed. A total of 198 fragments were found, of which 174 (87.88\%) were polymorphic. The PIC value ranged from $0.860-0.937$ with an average value of 0.914 . The GS ranged from $0.49-0.85$ with a mean of 0.71 . The dendrograms constructed by the UPGMA cluster indicate strong differentiation between the Thai sugarcane genotypes and the Hawaiian sugarcane genotypes. In addition, S. officinarum is the group most closely associated with modern sugarcane. The partial Sai nucleotide sequence of 16 sugarcane genotypes from Hawaii and Thailand comprised 608-692 bp, within exon 2. There were 49 single nucleotide polymorphisms (SNPs) and two sites of variation including insertion and deletion (In/Del). Sai nucleotide polymorphism data matrices produced a more refined phylogenetic tree that shows four distinct groups. The results derived from nucleotide sequencing were somewhat similar to those derived from the TRAP markers. Thus, the utilization of informative TRAP and Sai nucleotide sequencing for a genetic variation study can result in the selection of diverse sugarcane parents for trait of sucrose content.
\end{abstract}

KEYWORDS: Saccharum, phylogenetic tree, sucrose content, TRAP marker, soluble acid invertase

\section{INTRODUCTION}

Sugarcane is highly heterozygous and has complex aneuploids. It belongs to the subtribe Saccharinae of the tribe Andropogoneae. The genera Saccharum, Erianthus (sect. Rimpidium), Miscanthus (sect. Diantra), Sclerostachya, and Narenga constitute a closely related inbreeding group referred to as Saccharum complex ${ }^{1}$. The genus Saccharum contains six species, namely Saccharum officinarum $(2 \mathrm{n}=$ $80)$, S. spontaneum $(2 \mathrm{n}=40-128), S$. barberi $(2 \mathrm{n}$ $=81-124), S$. sinense $(2 \mathrm{n}=111-120)$, S. robustum $(2 \mathrm{n}=60-80)$, and $S$. edule $(2 \mathrm{n}=60,70,80)^{2}$. Most sugar-producing modern sugarcane cultivars are derived from interspecific hybridization between the domesticated species $S$. officinarum and its wild relative $S$. spontaneum and then backcrossing the progenies to the $S$. officinarum recurrent parents to recover favorable alleles for sugar content ${ }^{3}$. Consequently, modern sugarcane cultivars are interspecific hybrids with approximately $80 \%$ chromosomes from $S$. officinarum, 10-15\% chromosomes from S. spontaneum, and 5-10\% recombinant chromosomes ${ }^{4}$. For this reason, our study of genetic variation was focused on $S$. officinarum, S. spontaneum and $S$. robustum.

Attempts to increase sucrose accumulation have been made through conventional plant breeding methods and optimization of growing conditions ${ }^{5}$. Although this has resulted in improved commercial sugarcane cultivars, the selection procedure is very long and arduous. Limits certainly exist in the major physiological processes of photosynthesis, sucrose transport and metabolism. Currently, some enzymes 
involved in sucrose metabolism such as sucrose synthase, sucrose phosphate synthase and invertases have been identified, characterized, and evaluated for their roles in key regulatory steps ${ }^{6-8}$. Soluble acid invertase (SAI) has been suggested to be a key regulator for the sucrose accumulation in sugarcane stem parenchyma ${ }^{6}$.

Most of the progress made so far in sugarcane breeding programs has accentuated strategies and traits that improve sugar content with little or no effort geared towards the direct improvement of traits to maximize yield and quality ${ }^{9}$. One reason that has been proposed for lack of progress is the narrow genetic base of sugarcane cultivars. Moreover, the complexity of the sugarcane genome has limited classical genetic studies ${ }^{10}$. Therefore, objectives should be specifically designed to achieve certain well-set goals and appropriate germplasm must be utilized in the breeding program.

The earliest molecular genetic linkage maps of the progenitors of modern sugarcane such as Randomly Amplified Polymorphic DNA (RAPD), Restriction Fragment Length Polymorphism (RFLP), Simple Sequence Repeat (SSR), Amplified Fragment Length Polymorphism (AFLP), and SequenceRelated Amplified Polymorphism (SRAP) have been used to study genetic variation in this field crop ${ }^{11-13}$. These markers are ideal for genetic fingerprinting and linkage map construction because they are randomly distributed across the genome. They may not be related to some traits of interest to plant breeders. For a well-planned breeding program based on certain traits of interest, the genetic diversity information of available germplasm should be associated with functional polymorphism which can be measured using molecular markers derived from functionally characterized genes ${ }^{11-13}$. The Sugarcane Expressed Sequence Tag (SUCEST) Project produced more than 300000 ESTs ${ }^{14}$. Target Region Amplification Polymorphism (TRAP) is a simple PCR-based marker system that takes advantage of available EST database sequence information to generate polymorphic markers by targeting candidate genes ${ }^{15}$. TRAP markers are involved in designing a fixed primer of about 18 nucleotides from EST sequences or genes of interest and an arbitrary primer about the same length is designed with either AT- and GC-rich motifs that anneal to introns and exons, respectively ${ }^{15,16}$. The TRAP markers for sucrose- ${ }^{12}$, drought- ${ }^{13}$ and ligninrelated $^{9}$ genes were successfully applied to study the genetic variation in sugarcane. As an initial step in this direction, our research was conducted
Table 1 The 24 sugarcane genotypes used in this study.

\begin{tabular}{|c|c|c|}
\hline Genotype & Genus/species & Sugar content \\
\hline Lahaina $^{\mathrm{a} \dagger}$ & S. officinarum & $16.5 \%$ brix \\
\hline LA Purple ${ }^{\mathrm{a}^{\dagger}}$ & S. officinarum & 4.7\% pol dry basis \\
\hline KKU99-02 ${ }^{\mathrm{b} \dagger}$ & S. officinarum & $24.2 \%$ brix \\
\hline $\mathrm{MTP}^{\mathrm{b} \dagger}$ & S. officinarum & $23.9 \%$ brix \\
\hline $\mathrm{KK} 1^{\mathrm{b} \dagger}$ & S. officinarum & $25.0 \%$ brix \\
\hline $\mathrm{KK} 3^{\mathrm{b} \dagger}$ & S. officinarum & $23.6 \%$ brix \\
\hline $\mathrm{K} 88-92^{\mathrm{b} \dagger}$ & S. officinarum & $20.8 \%$ brix \\
\hline US56-14-4 ${ }^{\mathrm{a} \dagger}$ & S. spontaneum & Low $^{*}$ \\
\hline SES208 ${ }^{\mathrm{a}^{\dagger}}$ & S. spontaneum & Low $^{*}$ \\
\hline THA83-183 ${ }^{\mathrm{a} \dagger}$ & S. spontaneum & Low $^{*}$ \\
\hline S. spontaneum ${ }^{\mathrm{bi}}$ & 'S. spontaneum & $17.0 \%$ brix \\
\hline ThS $98-226^{\mathrm{b} \dagger}$ & S. spontaneum & $17.7 \%$ brix \\
\hline AP85-441 & S. spontaneum & Low ${ }^{*}$ \\
\hline MOL6081 ${ }^{\text {a† }}$ & S. robustum & Low $^{*}$ \\
\hline MOL6139a & S. robustum & Low* ${ }^{*}$ \\
\hline Timor Wild ${ }^{\mathrm{a} \dagger}$ & Erianthus & Low $^{*}$ \\
\hline $\mathrm{F} 1(10-9203)^{\mathrm{a} \dagger}$ & Saccharum spp. hybrid ${ }^{c}$ & High $^{*}$ \\
\hline $41-91^{\mathrm{b}}$ & Saccharum spp. hybrid ${ }^{\mathrm{d}}$ & $23.6 \%$ brix \\
\hline $41-86^{\mathrm{b}}$ & Saccharum spp. hybrid ${ }^{\mathrm{d}}$ & $25.1 \%$ brix \\
\hline $41-64^{b}$ & Saccharum spp. hybrid ${ }^{\mathrm{d}}$ & $17.1 \%$ brix \\
\hline $41-52^{\mathrm{b}}$ & Saccharum spp. hybrid ${ }^{\mathrm{d}}$ & $23.2 \%$ brix \\
\hline $41-37^{\mathrm{b}}$ & Saccharum spp. hybrid ${ }^{\mathrm{d}}$ & $17.7 \%$ brix \\
\hline $41-30^{\mathrm{b}}$ & Saccharum spp. hybrid ${ }^{\mathrm{d}}$ & $18.2 \%$ brix \\
\hline $41-4^{b}$ & Saccharum spp. hybrid ${ }^{\mathrm{d}}$ & $16.4 \%$ brix \\
\hline
\end{tabular}

a,b Sugarcane genotypes obtained from Sugarcane Germplasm Collection at HARC Maunawili Breeding Station, Oahu, Hawaii and Khon Kaen Field Crops Research Center, Khon Kaen, Thailand, respectively.

${ }^{c, d}$ Saccharum spp. hybrids derived from LA-purple $\times$ US56-14-4 and KK1 × ThS98-226, respectively.

$\dagger$ Their DNA fragments were sequenced.

"Exact values are not available.

to understand the molecular variation among some sugarcane genotypes grown in Hawaii and Thailand with respect to the genes involved in sucrose accumulation using the TRAP marker technique and partial Sai nucleotide polymorphism.

\section{MATERIALS AND METHODS}

\section{Plant material and DNA extraction}

A total of 24 genotypes (Table 1) were used in this study. Leaf tissues were sampled from each genotype grown either in the Sugarcane Germplasm Collection at the HARC Maunawili Breeding Station, Oahu, Hawaii or Khon Kaen Field Crops Research Center, Khon Kaen, Thailand. The samples were frozen immediately in liquid nitrogen and ground to powder for DNA extraction. Total genomic DNA was extracted using both the Plant DNeasy mini kit (Qiagen, Valencia, CA) and the CTAB procedure ${ }^{17}$ 
Table 2 Sequences of arbitrary reverse primers used for 24 genotypes of Saccharum complex with fixed forward Sai (CTCGCCATGCTCTACACG, NCBI accession no. JQ982494.1).

\begin{tabular}{|c|c|c|}
\hline Primer & Sequence $\left(5^{\prime}-3^{\prime}\right)$ & Reference \\
\hline ME2 & TGAGTCCAAACCGGAGC & $\mathrm{Li}$ and Quiros ${ }^{20}$ \\
\hline ME5 & TGAGTCCAAACCGGAAG & $\mathrm{Li}$ and Quiros ${ }^{20}$ \\
\hline ME7 & TGAGTCCTTTCCGGTCC & $\mathrm{Li}$ and Quiros ${ }^{20}$ \\
\hline EM5 & GACTGCGTACGAATTCAA & $\mathrm{Li}$ and Quiros ${ }^{20}$ \\
\hline EM6 & GACTGCGTACGAATTCCA & $\mathrm{Li}$ and Quiros ${ }^{20}$ \\
\hline EM8 & GACTGCGTACGAATTCAC & $\mathrm{Li}$ and Quiros ${ }^{20}$ \\
\hline ODD4 & AGGGTAGCG TCTGAGGA & Li et $\mathrm{al}^{22}$ \\
\hline ODD20 & TCGTTGTTATGGCTGGAGA & Li et $\mathrm{al}^{22}$ \\
\hline ODD56 & GAGAAAGGTATGAGTTGAAC & Li et $\mathrm{al}^{22}$ \\
\hline ODD66 & GATTTTGATTTACAGGAGAGA & Li et $\mathrm{al}^{22}$ \\
\hline ODD68 & AAAGGGAGACAGATATTTACA & Li et $\mathrm{al}^{22}$ \\
\hline ODD62 & AGGTGAGTAAGTTCGGACAT & Li et $\mathrm{al}^{22}$ \\
\hline
\end{tabular}

with some modifications for sugarcane. The concentrations of extracted DNA were estimated with a Nanodrop 1000 spectrophotometer (Nanodrop, Bethesda, MD) at $260 \mathrm{~nm}$. The DNA quality was evaluated based on the ratio of the spectrophotometer readings at 260 and $280 \mathrm{~nm}$. Only the high-quality DNA was stored at $-20^{\circ} \mathrm{C}$ for further analysis.

\section{TRAP primer design}

TRAP is a two-primer PCR marker technique ${ }^{15}$. The fixed forward primer was designed from EST sequences and the accompanied arbitrary reverse primer was designed to target introns or exons. In this study, the fixed primer was designed from only Sai gene, which is suggested to be a key regulator for sucrose accumulation of sugarcane. The primer was designed using the Primer3 software (http:// bioinfo.ut.ee/primer3-0.4.0). The optimum size, optimum $\mathrm{Tm}$, maximum $\mathrm{Tm}$ and minimum $\mathrm{Tm}$ were set at $18 \mathrm{nt}, 53^{\circ} \mathrm{C}, 55^{\circ} \mathrm{C}$, and $50^{\circ} \mathrm{C}$, respectively. The gene, GenBank accession number and designed primer sequence of Sai gene are given in Table 2 .

Arbitrary reverse primer sequences were obtained from the research articles by Li and Quiros ${ }^{16}$ and $\mathrm{Li}$ et $\mathrm{al}^{18}$ as shown in Table 2 . The basic structure of this primer includes three selective nucleotides at the $3^{\prime}$ end, four nucleotides of AT- or GCrich content in the core region, and 11 nucleotides as filler sequences at the $5^{\prime}$ end. The arbitrary primer is designed normally to target either the exonic (GC-rich) or the intronic (AT-rich) region of the genome. In addition, the basic rules of primer design, such as self-complementarity and maintenance of $40-60 \%$ GC content were upheld in designing both primers (Table 2). A total of 12 TRAP primer combinations were used in this study.

\section{TRAP PCR amplifications}

RAP PCR was performed following the protocol as described by $\mathrm{Hu}$ and Vick ${ }^{15}$ with some modifications. Each PCR reaction solution $(15 \mu \mathrm{l})$ consisted of $1 \times$ PCR buffer with $\left(\mathrm{NH}_{4}\right)_{2} \mathrm{SO}_{4}(75 \mathrm{mM}$ Tris$\mathrm{HCl}, 20 \mathrm{mM}\left(\mathrm{NH}_{4}\right)_{2} \mathrm{SO}_{4}, 0.01 \%$ (v/v) Tween 20, $\mathrm{pH} 8.8$ at $25^{\circ} \mathrm{C}$ ), $1.5 \mathrm{mM} \mathrm{MgCl}_{2}, 0.2 \mathrm{mM}$ dNTP, $1 \mathrm{U}$ Taq DNA polymerases (Thermo Scientific), $0.1 \mu \mathrm{M}$ of fixed primer, $0.5 \mu \mathrm{M}$ of arbitrary primer and 100 ng DNA templates. PCR was carried out by initially denaturing template DNA at $94^{\circ} \mathrm{C}$ for $1 \mathrm{~min}$, followed by 5 cycles at $94^{\circ} \mathrm{C}$ for $1 \mathrm{~min}, 35^{\circ} \mathrm{C}$ for $1 \mathrm{~min}$ and $72^{\circ} \mathrm{C}$ for $1 \mathrm{~min}$, followed by 35 cycles at $94^{\circ} \mathrm{C}$ for $1 \mathrm{~min}, 50^{\circ} \mathrm{C}$ for $1 \mathrm{~min}$ and $72^{\circ} \mathrm{C}$ for $2 \mathrm{~min}$, with final extension step at $72^{\circ} \mathrm{C}$ for $5 \mathrm{~min}$. Final PCR product was added with $2 \mu$ l stop buffer ( $5 \times$ loading dye with $10 \times$ SYBR gold nucleic acid gel stain) after the PCR completion and loaded onto a 1.5\% (w/v) agarose gel. Electrophoresis was conducted at 100 volts for $1 \mathrm{~h}$. The images were visualized and collected under a UV light transilluminator by gel 100 volts documentation system (Bio-Rad) and scored manually for presence or absence of bands/alleles.

\section{Data collection and statistical analysis}

Only readable and unambiguous polymorphic fragments in the digital images were scored manually as 1 for presence and 0 for absence in all genotypes. Allelic diversity at a given locus can be measured by PIC wherein a marker can distinguish two alleles taken at random from a population and it was calculated as PIC $=1-\sum f_{i}^{2}$, where $f_{i}$ is the frequency of the $i$-th allele ${ }^{19}$. Considering the number of alleles at a locus along with their relative frequencies in a given population, an estimate of the discriminatory power of a marker can be obtained by calculating the PIC value ${ }^{20}$. The binary interpretation was transferred to NTSYSpc $2.11 \mathrm{~S}^{21}$, in which a matrix of Dice's coefficient ${ }^{22}$ was used to calculate the pairwise genetic similarity, GS $=2 a /(2 a+b+c)$, matrices using the SIMQUAL procedure. The GS matrices were then employed to construct the dendrogram with the UPGMA algorithm ${ }^{23}$, using the SAHN clustering procedure ${ }^{23}$. All the dendrograms that could be produced from different combinations of tied similarity values were combined by majority rule into a consensus dendrogram with branch probabilities indicating the percentage of dendrograms 
Table 3 Amplification pattern of 7 and 10 sugarcane genotypes from Hawaii and Thailand evaluated by TRAP markers.

\begin{tabular}{lcccc}
\hline Primer & Band $^{\text {a }}$ & \multicolumn{2}{c}{ Polymorphic } & PIC \\
\cline { 3 - 4 } combination & observed & band & $\%$ & value \\
\hline Sai-ME2 & 22 & 22 & 100.00 & 0.941 \\
Sai-ME5 & 18 & 18 & 100.00 & 0.932 \\
Sai-ME7 & 30 & 30 & 100.00 & 0.948 \\
Sai-EM5 & 31 & 31 & 100.00 & 0.959 \\
Sai-EM6 & 18 & 17 & 94.44 & 0.921 \\
Sai-EM8 & 22 & 22 & 100.00 & 0.941 \\
Sai-ODD4 & 24 & 24 & 100.00 & 0.948 \\
Sai-ODD20 & 18 & 18 & 100.00 & 0.912 \\
Sai-BG56 & 25 & 25 & 100.00 & 0.946 \\
Sai-BG66 & 24 & 24 & 100.00 & 0.936 \\
Sai-BG68 & 21 & 21 & 100.00 & 0.939 \\
Sai-BG92 & 22 & 21 & 95.45 & 0.933 \\
\hline Total & 275 & 273 & - & - \\
Average & 22.9 & 22.8 & 99.27 & 0.938 \\
\hline
\end{tabular}

${ }^{a}$ The fragment size varies from $\sim 200-2000 \mathrm{bp}$.

which contain that subset.

\section{Analysis of Sai nucleotide polymorphism}

As the initial step in cloning Sai gene, specific primers were designed based on the flanked exon 2 of Sai gene (GenBank, JQ982494.1). The partial Sai gene ( $\sim 690$ bp) of S. officinarum, S. robustum, S. spontaneum, Eriantus and a sugarcane hybrid (Table 1) were then amplified by a pair of primers: the gene specific forward primer which has the same sequence as the fixed forward primer of TRAP marker (Table 2) and a reverse primer ( $5^{\prime}$ CTCCAAGGGATGGGCATC- $3^{\prime}$ ). The PCR recipe was similar to that for TRAP-PCR, except that $50 \mathrm{ng}$ genomic DNA was used as a template. Amplification was performed by the following thermal cycles: $94^{\circ} \mathrm{C}$ for $5 \mathrm{~min}$, followed by 35 cycles of $94^{\circ} \mathrm{C}$ for $30 \mathrm{~s}, 55^{\circ} \mathrm{C}$ for $40 \mathrm{~s}$, and $72^{\circ} \mathrm{C}$ for $30 \mathrm{~s}$ and then $72^{\circ} \mathrm{C}$ for $7 \mathrm{~min}$. The PCR products were separated on a $1.5 \%$ agarose gel and purified for sequencing. The sequencing analysis was conducted at the Sequencing Department, SolGent Co., Ltd. Sequence comparison and alignment analyses were performed using the MEGA $6^{24}$. Phylogenetic trees were constructed by MEGA 6 software based on the nucleotide sequences using the UPGMA method.

\section{RESULTS AND DISCUSSION}

The present study was carried out using TRAP markers to determine the genetic variation of 7 and 10
Table 4 Amplification pattern of 14 sugarcane genotypes from the Thailand collection evaluated by TRAP markers.

\begin{tabular}{|c|c|c|c|c|}
\hline \multirow{2}{*}{$\begin{array}{l}\text { Primer } \\
\text { combination }\end{array}$} & \multirow{2}{*}{$\begin{array}{c}\text { Band }^{\mathrm{a}} \\
\text { observed }\end{array}$} & \multicolumn{2}{|c|}{ Polymorphic } & \multirow{2}{*}{$\begin{array}{c}\text { PIC } \\
\text { value }\end{array}$} \\
\hline & & band & $\%$ & \\
\hline Sai-ME2 & 16 & 16 & 100.00 & 0.916 \\
\hline Sai-ME5 & 16 & 15 & 93.75 & 0.921 \\
\hline Sai-ME7 & 15 & 15 & 100.00 & 0.915 \\
\hline Sai-EM5 & 17 & 15 & 88.24 & 0.902 \\
\hline Sai-EM6 & 8 & 6 & 75.00 & 0.860 \\
\hline Sai-EM8 & 12 & 12 & 100.00 & 0.888 \\
\hline Sai-ODD4 & 19 & 16 & 84.21 & 0.925 \\
\hline Sai-ODD20 & 21 & 19 & 90.48 & 0.929 \\
\hline Sai-BG56 & 22 & 18 & 81.81 & 0.936 \\
\hline Sai-BG66 & 15 & 10 & 66.67 & 0.914 \\
\hline Sai-BG68 & 21 & 20 & 95.24 & 0.937 \\
\hline Sai-BG92 & 16 & 12 & 75.00 & 0.920 \\
\hline Total & 198 & 174 & - & - \\
\hline Average & 16.5 & 14.5 & 87.88 & 0.914 \\
\hline
\end{tabular}

${ }^{\text {a }}$ The fragment size varies from $\sim 200-2000 \mathrm{bp}$.

sugarcane genotypes from Hawaii and Thailand, respectively. The data obtained for each marker are presented in Table 3. The twelve TRAP primer combinations used for PCR amplification produced 275 amplified fragments, of which 273 (99.27\%) were polymorphic (Table 3 ). The total number of bands amplified by individual primer combinations ranged from 18-31 with an average of 23 bands per primer combination. The fragment size varied from $\sim 200-2000 \mathrm{bp}$. The band profile obtained using the Sai+BG66 primer pair in 17 sugarcane genotypes is shown in Fig. 1a. The PIC value ranged from 0.912 (Sai+ODD20 primer pair) to 0.959 (Sai+EM5 primer pair) with an average value of 0.938 . The GS by Dice's similarity coefficient ranged from 0.19 (Timor Wild/US56-14-4) to 0.81 (MTP3/KKU9902) with a mean of 0.44 (Table $5 \mathrm{a}$ ). A dendrogram which was constructed using the UPGMA method, shows genetic variation among the 17 sugarcane genotypes (Fig. 2a).

The 14 sugarcane genotypes from the Thailand collection with different sugar content were also assessed by TRAP markers. Of the 198 alleles amplified by 12 TRAP markers in the range of $\sim 20$ $2000 \mathrm{bp}, 174$ amplified fragments were found to be polymorphic with an average of 17 bands per primer combination (Table 4). Percentage of polymorphism was 87.88 . The band profile obtained using the Sai+BG66 primer pair in 14 sugarcane genotypes is shown in Fig. 1b. The PIC value ranged from 0.860 (Sai+EM6 primer pair) to 0.937 (Sai+BG68 

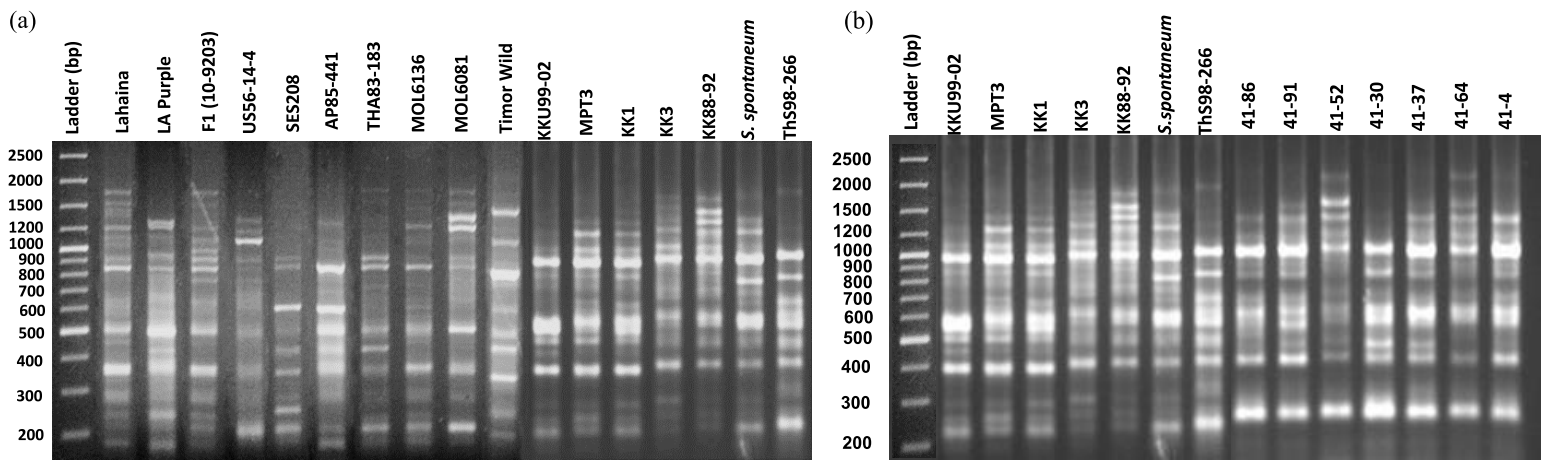

Fig. 1 Representative molecular profiling of (a) 7 and 10 sugarcane genotypes from Hawaii and Thailand and (b) 14 sugarcane genotypes from Thailand collection generated with the Sai+BG66 primer pair.
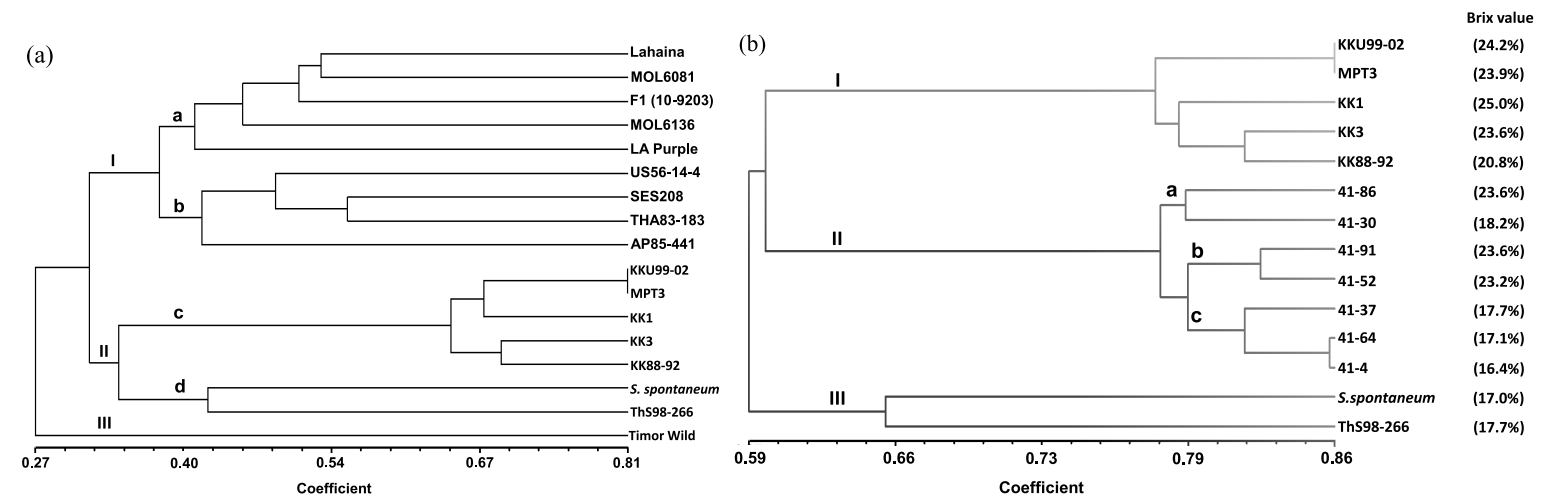

Fig. 2 Dendrograms generated from TRAP markers showing the grouping of (a) 7 and 10 sugarcane genotypes from Hawaii and Thailand and (b) 14 sugarcane genotypes from the Thailand collection based on Dice's similarity values.

primer pair) with an average value of 0.914. The GS by Dice's similarity coefficient ranged from 0.49 (ThS98-226/KK3) to 0.85 (MTP3/KKU99-02) with a mean of 0.71 (Table $5 \mathrm{~b}$ ). The dendrogram which was constructed using the UPGMA method is shown in Fig. 2b.

In our study, using TRAP markers resulted in high polymorphism (99.27 and 87.88\%). The complex genetic structure of sugarcane with high aneuploidy (80-140 homo(eo)logous chromosomes) may cause a high level of polymorphism ${ }^{12,25,26}$. Similar results were reported in Sachharum spp. by Lima et $\mathrm{al}^{27}$ using AFLP markers, by Srivastava and Gupta ${ }^{28}$ employing ISSR markers, and by Alwala et $\mathrm{al}^{12}$ using TRAP markers. Comparable PIC values in sugarcane were also found when TRAP markers alone ${ }^{11}$ or TRAP and AFLP markers ${ }^{13}$ were used. The differences in PIC values may result from different sets of sugarcane genotypes and different detection systems ${ }^{29}$.

The range of variation of Dice's GS values was estimated for the 17 sugarcane genotypes from
Hawaii and Thailand (0.19-0.85) and the 14 sugarcane genotypes from the Thailand collection (0.490.85). The GS among groups of species or genotypes was computed as an additional measure to assess the genetic variation (Table 5). The estimates showed that $S$. spontaneum had the least amount of similarity in the 17 sugarcane genotypes (mean $=0.34$ ) indicating that relatively higher level of heterozygosity and polymorphism exists within the species. This species is accepted as the most diverse of Saccharum spp. in terms of morphology, chromosome number and geographical distribution ${ }^{30,31}$. Compared with $S$. spontaneum, the genetic similarity among 14 sugarcane genotypes from the Thailand collection showed the least GS. The highest GS was obtained among the modern sugarcane cultivars (mean $=0.85$ ), followed by the group of sugarcane hybrids (mean $=0.70$ ). These results provide additional support that modern sugarcane cultivars have a narrow genetic base. A similar opinion is also expressed by Barnes and Bester ${ }^{10}$. 
Table 5 Genetic similarity (GS) estimates using TRAP markers on (a) 17 sugarcane genotypes from Hawaii and Thailand and (b) 14 sugarcane genotypes from the Thailand collection.

\begin{tabular}{|c|c|c|c|c|c|c|c|c|c|c|c|c|c|c|c|c|c|}
\hline (a) & 1 & 2 & 3 & 4 & 5 & 6 & 7 & 8 & 9 & 10 & 11 & 12 & 13 & 14 & 15 & 16 & 17 \\
\hline 1 Lahaina & 1 & & & & & & & & & & & & & & & & \\
\hline 2 LA Purple & 0.46 & 1 & & & & & & & & & & & & & & & \\
\hline 3 F1 (10-9203) & 0.50 & 0.46 & 1 & & & & & & & & & & & & & & \\
\hline 4 US56-14-4 & 0.30 & 0.31 & 0.45 & 1 & & & & & & & & & & & & & \\
\hline 5 SES208 & 0.37 & 0.35 & 0.38 & 0.53 & 1 & & & & & & & & & & & & \\
\hline 6 AP85-441 & 0.35 & 0.41 & 0.35 & 0.39 & 0.47 & 1 & & & & & & & & & & & \\
\hline 7 THA83-183 & 0.38 & 0.28 & 0.47 & 0.45 & 0.55 & 0.4 & 1 & & & & & & & & & & \\
\hline 8 MOL6136 & 0.44 & 0.38 & 0.42 & 0.31 & 0.4 & 0.39 & 0.5 & 1 & & & & & & & & & \\
\hline 9 MOL6081 & 0.53 & 0.36 & 0.51 & 0.35 & 0.43 & 0.34 & 0.49 & 0.51 & 1 & & & & & & & & \\
\hline 10 Timor Wild & 0.27 & 0.29 & 0.34 & 0.19 & 0.24 & 0.37 & 0.31 & 0.23 & 0.23 & 1 & & & & & & & \\
\hline 11 KKU99-02 & 0.30 & 0.40 & 0.37 & 0.38 & 0.34 & 0.37 & 0.29 & 0.28 & 0.34 & 0.28 & 1 & & & & & & \\
\hline 12 MPT3 & 0.33 & 0.36 & 0.35 & 0.39 & 0.35 & 0.31 & 0.3 & 0.26 & 0.33 & 0.22 & 0.81 & 1 & & & & & \\
\hline 13 KK1 & 0.30 & 0.42 & 0.34 & 0.36 & 0.37 & 0.35 & 0.28 & 0.26 & 0.3 & 0.31 & 0.67 & 0.68 & 1 & & & & \\
\hline 14 KK3 & 0.33 & 0.43 & 0.34 & 0.31 & 0.33 & 0.35 & 0.25 & 0.25 & 0.34 & 0.22 & 0.61 & 0.61 & 0.63 & 1 & & & \\
\hline 15 KK88-92 & 0.30 & 0.37 & 0.34 & 0.35 & 0.36 & 0.32 & 0.29 & 0.24 & 0.35 & 0.24 & 0.7 & 0.68 & 0.64 & 0.69 & 1 & & \\
\hline 16 S. spontaneum & 0.28 & 0.24 & 0.27 & 0.29 & 0.25 & 0.28 & 0.32 & 0.25 & 0.27 & 0.26 & 0.36 & 0.41 & 0.4 & 0.45 & 0.49 & 1 & \\
\hline 17 ThS98-266 & 0.26 & 0.36 & 0.31 & 0.29 & 0.26 & 0.38 & 0.32 & 0.31 & 0.23 & 0.31 & 0.25 & 0.27 & 0.27 & 0.24 & 0.31 & 0.43 & 1 \\
\hline (b) & 1 & 2 & 3 & 4 & 5 & 6 & 7 & 8 & 9 & 10 & 11 & 12 & 13 & 14 & & & \\
\hline 1 KKU99-02 & 1 & & & & & & & & & & & & & & & & \\
\hline 2 MPT3 & 0.85 & 1 & & & & & & & & & & & & & & & \\
\hline 3 KK1 & 0.75 & 0.78 & 1 & & & & & & & & & & & & & & \\
\hline 4 KK3 & 0.78 & 0.79 & 0.78 & 1 & & & & & & & & & & & & & \\
\hline 5 KK88-92 & 0.74 & 0.76 & 0.78 & 0.81 & 1 & & & & & & & & & & & & \\
\hline 6 S. spontaneum & 0.60 & 0.67 & 0.61 & 0.62 & 0.68 & 1 & & & & & & & & & & & \\
\hline 7 ThS98-226 & 0.52 & 0.58 & 0.52 & 0.49 & 0.53 & 0.64 & 1 & & & & & & & & & & \\
\hline $841-86$ & 0.60 & 0.66 & 0.64 & 0.60 & 0.60 & 0.61 & 0.65 & 1 & & & & & & & & & \\
\hline $941-91$ & 0.62 & 0.60 & 0.67 & 0.6 & 0.59 & 0.57 & 0.61 & 0.82 & 1 & & & & & & & & \\
\hline $1041-52$ & 0.60 & 0.62 & 0.65 & 0.61 & 0.62 & 0.57 & 0.61 & 0.77 & 0.84 & 1 & & & & & & & \\
\hline $1141-30$ & 0.56 & 0.59 & 0.61 & 0.59 & 0.59 & 0.56 & 0.64 & 0.80 & 0.80 & 0.77 & 1 & & & & & & \\
\hline $1241-37$ & 0.59 & 0.61 & 0.64 & 0.60 & 0.60 & 0.58 & 0.62 & 0.80 & 0.81 & 0.80 & 0.83 & 1 & & & & & \\
\hline $1341-64$ & 0.58 & 0.59 & 0.60 & 0.60 & 0.60 & 0.56 & 0.62 & 0.77 & 0.82 & 0.81 & 0.78 & 0.85 & 1 & & & & \\
\hline $1441-4$ & 0.58 & 0.60 & 0.63 & 0.58 & 0.59 & 0.55 & 0.63 & 0.80 & 0.84 & 0.78 & 0.80 & 0.83 & 0.87 & 1 & & & \\
\hline
\end{tabular}

\section{Cluster Analysis}

The UPGMA dendrogram of the 17 sugarcane genotypes from Hawaii and Thailand generated by TRAP markers is shown in Fig. 2a. The dendrogram derived from cluster analysis reveals three clusters among $S$. officinarum, S. robustum, S. spontaneum, Eriantus and the sugarcane hybrid. Cluster I possesses only the sugarcane genotypes from the Hawaii collection having two sub-clusters: a and b. Sub-cluster a consists of $S$. officinarum, S. spontaneum, and F1 hybrid (10-9203), which has the parents from the cross between LA Purple and US5614. Sub-cluster b comprises only S. robustum. Cluster II possesses only the sugarcane genotypes from the Thailand collection having two sub-clusters: c and d, which are separated into $S$. officinarum and
S. spontaneum, respectively. In addition, Erianthus is identified as an out-group with very less GS (mean $=0.27$ ), Cluster III. Based on the dendrogram in Fig. 2a, the Thai sugarcane genotypes are different from the Hawaiian sugarcane genotypes. Our result indicates that there is strong differentiation between Saccharum and Erianthus. This is consistent with the results reported by Selvi et $\mathrm{al}^{25}$ and Alwala et $\mathrm{al}^{12}$ using SSR and TRAP markers, respectively.

In the 14 sugarcane genotypes from the Thailand collection, the dendrogram derived from cluster analysis reveals three clusters among $S$. officinarum, the sugarcane hybrid and $S$. spontaneum (Fig. 2b). Cluster I possesses only modern sugarcane cultivars belonging to $S$. officinarum with the highest GS (mean $=0.85$ ). Cluster II possesses the sugarcane hybrid which has the parents from the 
cross between KK1 and ThS98-226. This cluster has three sub-clusters: a, b and c. The Sacchrum hybrid No. 41-86 and 41-30 are in sub-cluster a while No. 41-91 and 41-52 are in sub-cluster b. All of them contain high sucrose content. They are more closely related to modern sugarcane cultivars. The Sacchrum hybrid No. 41-37, 41-64, and 41-4 are in subcluster c. They have low sucrose content and are more closely related to wild sugarcane genotypes. In addition, the wild sugarcane $S$. spontaneum, is identified as an out-group. It is in Cluster III.

Among the Saccharum spp. employed in our research, S. officinarum is the group most closely associated with modern sugarcane cultivars. This close association is to be expected since $S$. officinarum is one of the progenitor parents of modern sugarcane and was used as the recurrent parent during the breeding of modern sugarcane. As a result, the modern cultivars have an $80-85 \%$ genetic background of $S$. officinarum and hence the closer relationship with modern sugarcane cultivars $4,32,33$.

Though the differences in similarity coefficients of sugarcane cultivars were not large, the subgrouping reflects considerable diversity among sugarcane cultivars for the sucrose-related genes, due possibly to the polyploid nature and diverse background of sugarcane genome. Similar observations were made by Alwala et $\mathrm{al}^{12}$ and Creste et $\mathrm{al}^{13}$ using TRAP markers derived from sucrose- and drought-related genes.

Based on our results, it is reasonable to group sugarcane genotypes according to their sucrose content using TRAP markers. This indicates that there may be the difference in nucleotide sequence of Sai gene. Therefore, the partial nucleotide sequencing of Sai gene derived from the Hawaiian and Thai sugarcane cultivars was carried out.

\section{Sai nucleotide polymorphism}

The partial Sai nucleotide sequence of the 16 sugarcane genotypes comprised 608-692 bp, within exon 2. A BLASTN search for these nucleotide sequences on the Basic Local Alignment Search Tool site showed that all similar fragments were located on the Sai sequence of sugarcane, with identity percentages of 95-99 (data not shown).

A BLASTP search using the deduced pre-protein sequence of SAI as a query revealed that the predicted SAI protein sequence had high (97-99\%) homology. This was similar to the SAI proteins of sugarcane, except in SES208, AP85-441 and THA83-183 of which amino acid sequences did not match with those in the SAI protein database (data

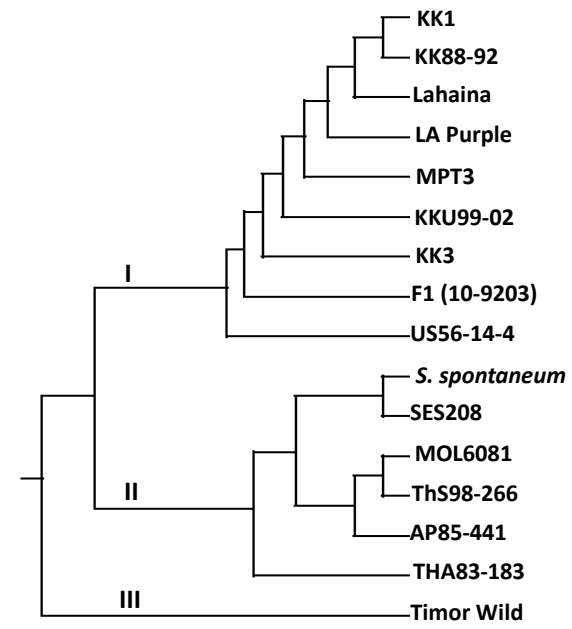

Fig. 3 Phylogenetic tree generated from nucleotide sequence showing the grouping of 16 sugarcane genotypes using the UPGMA method based on Dice's similarity coefficient.

not shown).

There were 49 SNPs and two sites of variation including In/Del sites among the 16 genotypes. Of the 49 SNPs, five were $\mathrm{A} / \mathrm{T}$ alterations, five were $\mathrm{A} / \mathrm{C}$ alterations, four were $\mathrm{A} / \mathrm{G}$ alterations, seven were $\mathrm{C} / \mathrm{T}$ alterations, two were $\mathrm{G} / \mathrm{T}$ alterations and 26 were $C / G$ alterations (data not shown). This indicates that the Sai gene of 16 sugarcane genotypes are different at the DNA level. The phylogenetic tree obtained by the UPGMA method based on Dice's similarity coefficient is illustrated in Fig. 3.

Sai nucleotide polymorphism data matrices produced a more refined phylogenetic tree that shows the association between intra- and intergroups of wild sugarcane and cultivated sugarcane. The cluster analysis had formed four distinct groups (Fig. 3). The majority of wild sugarcane, except US56-144 and THA83-183, is in group I whereas all of the modern sugarcane cultivars are in group II. Groups III and IV consist of THA83-183 and Timor Wild, respectively. The results derived from nucleotide sequencing were somewhat similar to those derived from the TRAP marker technique. The modern sugarcane cultivars can be separated from the wild sugarcane. This proves the utility and significance of Sai nucleotide sequencing system in a sugarcane genetic variation study. Thus, the utilization of informative TRAP and Sai nucleotide sequencing for a genetic variation study can result in the selection of diverse sugarcane parents for trait of sucrose content. 


\section{CONCLUSION}

Recently, sugarcane is projected as one of the most important sugar crops due to its ability to produce high sucrose. Hence, development of genotypes with high sucrose yield is a major objective of sugarcane breeders aiming to develop what is popularly called 'sugar cane'. In this context, the knowledge of the amount and distribution of genetic variation with respect to sucrose genes within the Saccharum complex will contribute much to the success of such breeding programs. Sucrose gene-based TRAP markers used in this study classified members of the Saccharum complex broadly according to previously established genetic relationships in the order of Miscanthus $>$ Erianthus $>$ S. spontaneum $>$ S. robustum/S. barberi/S. sinense $>$ S. officinarum/cultivars. Also revealed in this study was the genetic variation or relationships among genotypes within a species. This information can be useful to a breeder when deciding which individuals to use in initiating a breeding program. Miscanthus and Erianthus are known for their large stature and high dry matter content. The intergeneric hybridization between highly diverse Miscanthus/Erianthus with comparatively less diverse Saccharum germplasm could result in greater sugar-yielding cultivars suitable to a wider geographical range of cultivation. Furthermore, use of more robust functional markers such as single nucleotide polymorphism and genic SSRs derived from all the genes involved in the sucrose accumulation pathway, could be developed with higher success, in addition to biotechnological interventions, to facilitate breeding for energy cane development.

Acknowledgements: We would like to thank Mr. Werapon Ponrugdee of Field and Renewable Energy Crops Research Institute, Department of Agriculture, Ministry of Agriculture and Cooperatives, Bangkok, Thailand for providing the sugarcane samples. Thanks are also due to Dr. Ruizong Jia for his technical assistance given to the first author while he was conducting part of his thesis work at HARC, Waipahu, Hawaii, USA. Research facilities provided by Khon Kean Field Crops Research Center and Hawaii Agriculture Research Center are highly appreciated. Financial support was made available by the Thailand Research Fund's Royal Golden Jubilee Ph.D. Program (Grant No. 4.B.KK/52/C.1).

\section{REFERENCES}

1. Mukherjee SK (1957) Origin and distribution of Saccharum. Bot Gaz 119, 55-61.
2. Brandes EW (1958) Sugarcane (Saccharum officinarum L.): origin, classification and characteristics. In: Artschwager E, Brandes EW (eds) USDA Handbook 122, US Department of Agriculture, Washington DC, pp 1-35.

3. Jannoo N, Grivet L, David J, D'Hont A, Glaszmann JC (2004) Differential chromosome pairing affinities at meiosis in polyploid sugarcane revealed by molecular markers. Heredity 93, 460-467.

4. Bowen JE (1972) Sugar transport in immature internodal tissue of sugarcane. Mechanism and kinetics of accumulation. J Plant Physiol 49, 82-86.

5. Silva JA, Bressiani JA (2005) Sucrose synthase molecular marker associated with sugar content in elite sugarcane progeny. Genet Mol Biol 28, 294-298.

6. Zhu YJ, Komor E, Moore PH (1997) Sucrose accumulation in the sugarcane stem is regulated by the difference between the activities of soluble acid invertase and sucrose phosphate synthase. Plant Physiol 115, 609-616.

7. Lingle SE (1999) Sugar metabolism during growth and development in sugarcane internodes. Crop Sci 39, 480-486.

8. Pan YQ, Luo HL, Li YR (2009) Soluble acid invertase and sucrose phosphate synthase: key enzymes in regulating sucrose accumulation in sugarcane stalks. Sugar Tech 11, 28-33.

9. Suman A, Ali K, Arro J, Parco AS, Kimbeng CA, Baisakh N (2012) Molecular diversity among members of the Saccharum complex assessed using TRAP markers based on lignin-related genes. Bioenergy Res 5, 197-205.

10. Barnes JM, Bester AE (2000) Genetic mapping in sugarcane: prospects and progress in the South African sugar industry. SASTA 74, 117-119.

11. Alwala S, Kimbeng CA, Gravois CA, Bischoff KP (2006) TRAP, a new tool for sugarcane breeding: comparison with AFLP and coefficient of percentage. ASSCT 26, 62-86.

12. Alwala S, Suman A, Arro JA, Vermis JC, Kimbeng CA (2006) Target region amplification polymorphism (TRAP) for accessing genetic diversity in sugarcane germplasm collections. Crop Sci 46, 448-455.

13. Creste S, Accoroni KAG, Pinto LR, Vencovsky R, Gimenes MA, Xavier MA, Landell MGA (2010) Genetic variability among sugarcane genotypes based on polymorphisms in sucrose metabolism and drought tolerance genes. Euphytica 172, 435-446.

14. Vettore AL, Da Silva FR, Kemper EL, Arruda P (2001) The libraries that made SUCEST. Genet Mol Biol 24, $1-7$.

15. Hu JG, Vick BA (2003) Target region amplification polymorphism: a novel marker technique for plant genotyping. Plant Mol Biol Report 21, 289-294.

16. Li G, Quiros CF (2001) Sequence related amplified polymorphism (SRAP), a new marker system based on a simple PCR reaction: its application to mapping 
and gene tagging in Brassica. Theor Appl Genet 103, 455-461.

17. Hoisington D, Khairallah M, Gonzalez-de-Leon D (1994) Laboratory Protocols: CIMMYT Applied Molecular Genetics Laboratory, Mexico DF, Mexico.

18. Li QY, Dong SJ, Zhang WY, Lin RQ, Wang CR, Qian DX, Lun ZR, Song HQ, et al (2009) Sequence-related amplified polymorphism, an effective molecular approach for studying genetic variation in Fasciola spp. of human and animal health significance. Electrophoresis 30, 403-409.

19. Weir B (1990) Genetic Data Analysis: Methods for Discrete Population Genetic Data, Sinauer Associates, Sunderland.

20. Vuylsteke M, Mank R, Brugmans B, Stam P, Kuiper M (2000) Further characterization of AFLP data as a tool in genetic diversity assessments among maize (Zea mays L.) inbred lines. Mol Breed 6, 265-276.

21. Rohlf FJ (1998) NTSYS-PC Numerical Taxonomy and Multivariate Analysis System, Exeter Software, New York.

22. Dice LR (1945) Measures of the amount of ecologic association between species. Ecology 26, 297-302.

23. Sneath HA, Sokal RR (1973) Numerical Taxonomy, W. H. Freeman and Company, San Francisco.

24. Tamura K, Stecher G, Peterson D, Filipski A, Kumar S (2013) MEGA6: molecular evolutionary genetics analysis version 6.0. Mol Biol Evol 30, 2725-2729.

25. Selvi A, Nair NV, Balasundaram N, Mohapatra T (2003) Evaluation of maize microsatellite markers for genetic diversity analysis and fingerprinting in sugarcane. Genome 46, 394-403.

26. Suman A, Kimbeng CA, Edme SJ, Vermis J (2008) Sequence related amplified polymorphism (SRAP) markers for accessing genetic relationship and diversity in sugarcane germplasm collections. Plant Genet Resour 6, 222-231.

27. Lima MLA, Garcia AAF, Oliveira KM, Matsuoka S, Arizono H, De Souza CL Jr, De Souza AP (2002) Analysis of genetic similarity detected by AFLP and coefficient of parentage among genotypes of sugarcane (Saccharum spp.). Theor Appl Genet 104, 30-38.

28. Srivastava S, Gupta P (2008) Inter simple sequence repeat profile as a genetic marker system in sugarcane. Sugar Tech 10, 48-52.

29. Singh RK, Srivastava S, Singh SP, Sharma ML, Mohopatra T, Singh NK, Singh SB (2008) Identification of new microsatellite DNA markers for sugar and related traits in sugarcane. Sugar Tech 10, 327-333.

30. Daniels J, Roach BT (1987) Taxonomy and evolution. In: Heinz DJ (ed), Sugarcane Improvement through Breeding, Elsevier, Amsterdam, pp 7-84.

31. Devarumath RM, Kalwade SB, Kawar PG, Sushir KV (2012) Assessment of genetic diversity in sugarcane germplasm using ISSR and SSR markers. Sugar Tech 14, 334-344.

32. Bhat S, Gill SS (1985) The implication of $2 \mathrm{n}$ egg gametes in nobilization and breeding of sugarcane. Euphytica 34, 377-384.

33. Sreenivasan TV, Ahloowalia BS, Heinz DJ (1987) Cytogenetics. In: Heinz DJ (ed), Sugarcane Improvement through Breeding, Elsevier, Amsterdam, pp 211-253. 